\title{
DEVELOPING AN ACTIVE LEARNING EXPERIENCE FOR ACTIVE LEARNING COURSES.
}

\author{
Ahmed. Z. Salem. \\ Faculty of Engineering, Civil Eng. Dept.
}

\begin{abstract}
The need to blueprint a certain composition of Active Learning activities arises upon designing the learning experiences for a certain learning objective. Also it rises when designing the proper learning environment that leads the students in the right direction to achieve this objective. The precise succession of these activities, being before, inside, or after the class will lead the student to create their knowledge according to the constructivism theory for attaining their learning objective. In the literature, there are so resourceful sorts of activities that teacher can initiate to the students in this regards. For instance, Salem, A. Z. [1] has proposed a helping mechanism to design learning experiences for Active Learning courses. This mechanism intended at addressing the specific need to convert the learning objectives seeking certain Bloom's taxonomy domains of learning into a class's learning experiences. It offers a road map that offers many alternatives for any particular design. This mechanism also counted for the time component of the learning experiences. Examples were provided to demonstrate the use of the helping mechanism, varying from simple to complex designs. Surely, it is hard to think of the design of learning experience as a mechanized process because it is a composition of both art and science, but this mechanism is offering a good starting point. In this paper, we propose an answer for the questions "what type, duration, and collection of activities that may lead to achieve the evaluation level learning objective specifically?" and the question "How to assess both the success of this learning experience design and the student achievement?" This paper introduces an implementation of this helping mechanism to design a learning experience that targets the "evaluation" level of learning and takes also the affective domain three levels, namely "receiving, responding and valuing" into concern. The designed learning experience was applied in a course at college level, introducing the engineering design process to students. Evaluation of this learning experience showed that, it fulfilled its objectives.
\end{abstract}

\section{Keywords: Active Learning, Design College Course, Learning Experience, Class Environment.}

\section{INTRODUCTION}

Designing a learning experience that helps the students to achieve a certain level of learning is by nature an iterative process $[1,2,3]$. The teacher has to devise an initial design on paper $[2$, $3]$, implement it in reality, and then after assess its degree of success $[4,5]$. This sequence would form the first application cycle of the design. Upon completion of this cycle, it would be clear where the design needs improvements and what are the shortcomings. This is where the first redesign will take place. Then the next application cycle will follow. The more application cycles, the better the design becomes.

There are so many researchers offering solid guidelines for designing the learning experience in the literature such as $[2,3,6,7]$ for examples. However, few are providing in class detailed progression of activities that are both custom made to the classes sequences and also considering each class time duration [1].

We consider here an initial design that forms a solid starting point for a learning experience (LE) to enable the students to reach the evaluation level. We utilize the LE design helping 
mechanism adopted in [1] to achieve our thought off design. This design is targeting a college's level students, studying engineering design process $[6,7]$ at the sophomore level.

\section{LEARNING ACTIVITIES CLASSIFICATION TABLE AND RULES. \\ 2.1 Learning Activities Classification Table.}

We adopt in this work the same learning activities classification table as in [1]. These activities were complied in [1] based on [17] to [24]. We used only a subset of this table here as needed for our particular LE design. This subset is provided in Appendix A.

\subsection{Learning Activities Classification rules.}

We summarize the classification rules [1] here for completeness of this paper.

2.2.1 An activity belongs to a specific level of learning if it involves any one or more verbs of those verbs defined at that level of learning $[8,9,10]$.

2.2.2 An activity that belongs to a deeper level of learning does cover all the preceding levels of learning $[8,9]$.

2.2.3 Each activity is given a symbolic abbreviation at the left most column of the table in Appendix A, for ease of use. This symbol is a combination of learning level first letter and a serial number.

2.2.4 Each activity is given a time frame indicator letter, low (L), medium (M), and high (H), according to the time it requires.

2.2.5 Each activity is given a letter to indicate where it takes place. The letter $\mathbf{B}$ indicates it is done before class to prepare the students for the class, the letter I indicates it is done in the classroom and finally the letter $\mathbf{A}$ indicates it is done after the class.

2.2.6 Each activity is given an affective domain level classification symbol according to its contribution to that level. $\mathbf{R C}$ is for receive, $\mathbf{R S}$ is for respond, and $\mathbf{V}$ is for value.

\section{LEARNING EXPERIENCE DESIGN}

We adopt here the full spectrum of Bloom's taxonomy in the cognitive domain $[1,2,6]$; namely Access, Knowledge, Comprehension, Application, Analysis, Synthesis, and Evaluation $[8,9,10]$. The affective domain that is spanning, receive, respond, and value levels is integrated here as the required environment to assure the success of the LE.

The LE itself is modeled after [11], as a sequence of Input, Process, and Output activities. Even if a LE does include several mini LE's, each one of them is modeled also according to these three phases. Figure 1 below shows a typical model of this kind.

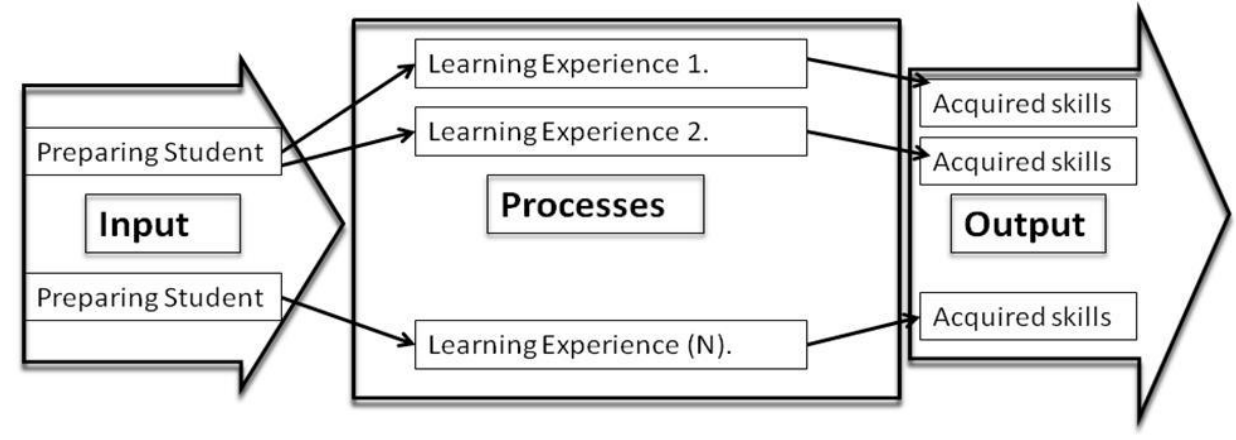

Figure 1. Schematic of a Learning Experience model.

According to Bloom's taxonomy, for the students to reach the evaluation level of learning, they would have to pass through all the preceding levels of learning mentioned above. Thus we propose hear an integrated design of the learning experiences that encompass all levels, build the required environment and casted in the above model. Figure 2 below shows how all levels of learning are modeled such that every level is an input for the next level. 


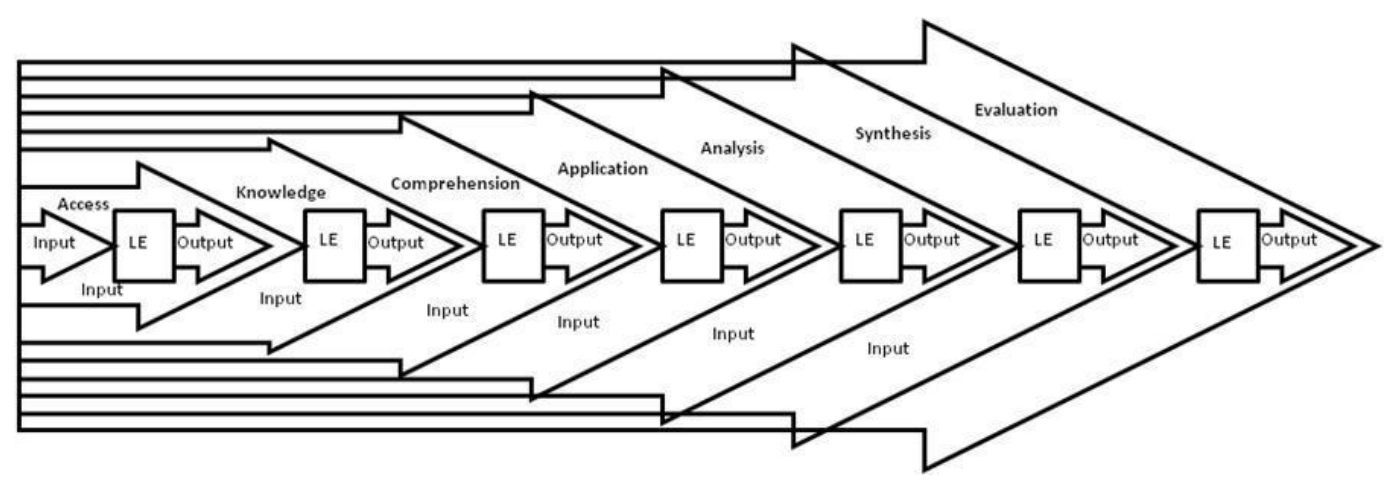

Figure 2. Casting the sequence of LE's in the input-process-output model.

We utilize here the combinatorial road map of [1] to design each of the stages of the complete LE as shown in the following section.

\section{HOW IT WORKS.}

\subsection{Review of the design aid mechanism.}

Using the design aid mechanism, we can set a roadmap to draft an initial design of the LE. This roadmap sequence has the following six steps:

4.1.1 Cast the learning objective (LO) into BTDL to determine the level we want the learner to achieve at each domain through the LE. Omit all other higher levels that are excluded from the LO.

4.1.2 Select the entire set of each level of BTDL that is needed for the LO.

4.1.3 Specify the allocated time for each phase of B, I, and A as L, M, or H.

4.1.4 Pick up from every set the activities that can be carried out within the specified time allocation at B, I, and A. Try many combinatorial formations to reach one that comfortably suit the timing.

4.1.5 Narrow down this selection based on the affective domain targeted levels.

4.1.6 Streamline and/or combine if possible the selected activities to form a LE that incorporates accurate assessment for each activity outcome.

\subsection{Learning experiences sequence.}

We start by considering a specific LE. Let us assume a situation where we want to help the students to construct their mental model [11] to reach the evaluation level about a particular material (assume, a certain chapter in the class material or so) in a course about engineering design process. In terms of Bloom's taxonomy, the LO here is "the students develop their abilities to access information, gain knowledge, reach comprehension, apply their understanding, analyze the results, synthesize a mini project, and finally successfully evaluate it". Casting the LO this way covers both the first and second steps of the roadmap above.

Suppose that this course is two credit hours and meeting three times a week; a total of six contact hours. Such a course needs the students to work twelve hours on average outside the class. We then have to allocate learning activities for a sum of eighteen hours a week; six of them are in classroom. Applying the LE model in Figures 1, and 2, we propose the following time allocation for each LE in Table 1 below. The table shows that the whole LE activities will consume 18 hours in-class activities ( 3 weeks of the academic calendar) and 32 combined hours of before and after-class activities. This fulfils step 3 in the above section's roadmap.

Table 1: Time allocation for all LE stages.

\begin{tabular}{|c|c|c|c|}
\hline LE & Input (hours) & Process (hours) & Output (hours) \\
\hline Access & 0 & 2 & 0 \\
\hline knowledge & Access & 2 & 4 \\
\hline Comprehension & knowledge & 2 & 4 \\
\hline Application & Comprehension & 2 & 4 \\
\hline Analysis & Application & 2 & 4 \\
\hline Synthesis & Analysis & 6 & 12 \\
\hline Evaluation & Synthesis & 2 & 4 \\
\hline TOTAL & & 18 & 32 \\
\hline
\end{tabular}


In the following subsections, after composing the LE, we will incorporate and then streamline at each level of learning some activities that serve as assessment tools to evaluate the success of the LE [13, 14, 15, 16, 24]. This will satisfy the last three steps in the roadmap.

\subsubsection{Access and Knowledge levels of learning's experience}

We combine the Access and Knowledge levels to form the first step in the LE design where the Access LE constitutes the Knowledge LE Input. This combination is called for by the fact that, some activities of the Knowledge LE do augment those of the Access LE to form the Input phase. The time allocation for this LE (as per Table 1 above) calls for two hours for Access LE, two hours for in-class Knowledge LE, and four hours for after-class activities. Figure 3 below shows the design of learning activities sequence for these two levels. Each activity is defined and classified in the activities table in Appendix A.

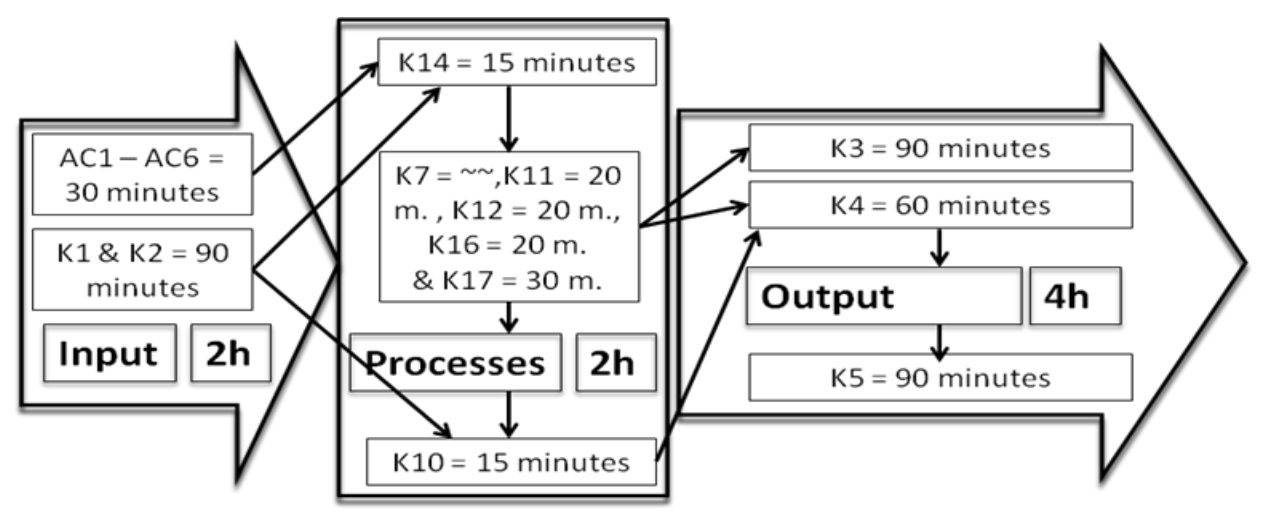

Figure 3. Proposed LEs for Access \& Knowledge levels.

Analysis: Each of the proposed LE activities should lead to the next, fits the time frame, and also has its assessment component. According to this design, students have to do AC1 to AC6 in addition to K1 \& K2 in phase B. At phase I, they do K14, and then they do process activities ends up with K10. After the class, they complete $\mathrm{K} 3$ to $\mathrm{K} 5$ for the A phase. It worth mentioning that, K14 is the assessment component for B, K10 is the assessment components for I, and the grading of K3 and K5 serves as the assessment component for A. This LE introduces eleven RC's, six RS', and 8 V's activities respectively. Thus, this LE indeed covers required levels of learning.

\subsubsection{Comprehension and Application levels of learning's experience}

We combine also the Comprehension and Application LE's in this step. This is necessitated by the fact that some Comprehension level activities are merged with some Application level activities to form the process stage on this LE. The time slots for this LE is two hours for Input, two hours for Process and four hours for Out, as listed in Table 1. Figure 4 below shows the design of learning activities sequence for these two levels, utilizing the table in Appendix A.

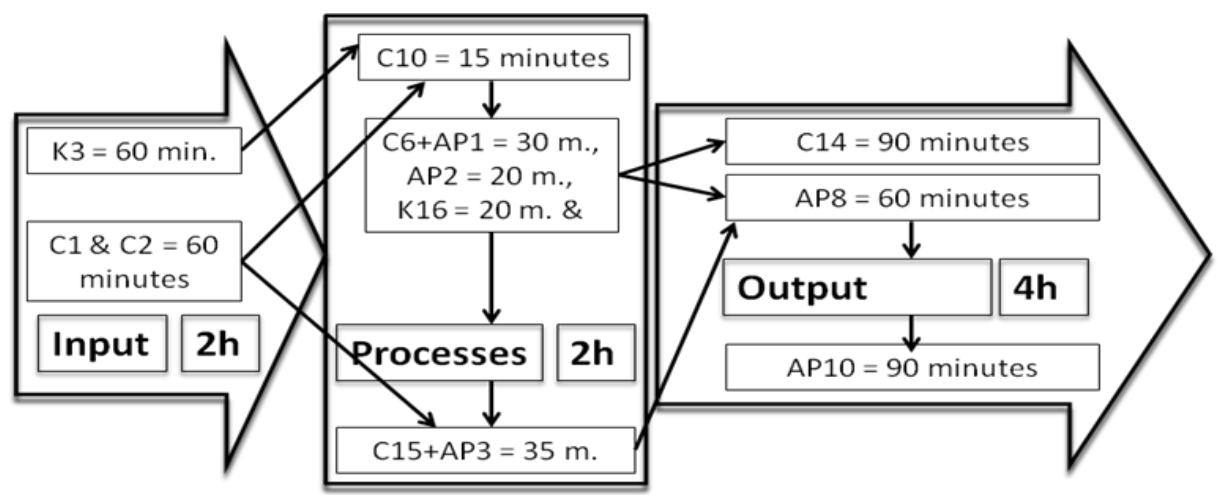

Figure 4. Proposed LEs for Comprehension \& Application levels.

Analysis: In phase B, students practice through K3, C1 and C2; modifying the textbook examples and read its problem individually, apply problem solving techniques and perform brainstorming on using the ideas of the subject. In phase $\mathbf{I}$, once in classroom, the students will take a written comprehension test about restating or reorganizing the facts of the subject 
in C10. They will then perform Comprehension then Application activities. In phase A, students will deepen their Comprehension and Application skills. To conclude, the grading of $\mathrm{C} 2$ and $\mathrm{C} 10$ are the assessment components for phase $\mathbf{B}$, grading of C15 and AP3 is the assessment component for phase $\mathbf{I}$, and the grading of both AP8 and AP10 is the assessment component of phase A. This LE introduces two RC's, nine RS', and ten V's activities respectively. Thus, this LE indeed covers required levels of learning.

\subsubsection{Analysis level of learning's experience.}

We select a sequence of activities that fits the time frame assigned for the Analysis level LE as in Table 1. Considering the Input is the Output of the Comprehension and Application levels LE's, we only have to streamline activities for two hours in-class and four hours afterclass activities. Figure 5 below shows this sequence of activities. Each activity is defined and classified the table in Appendix A.

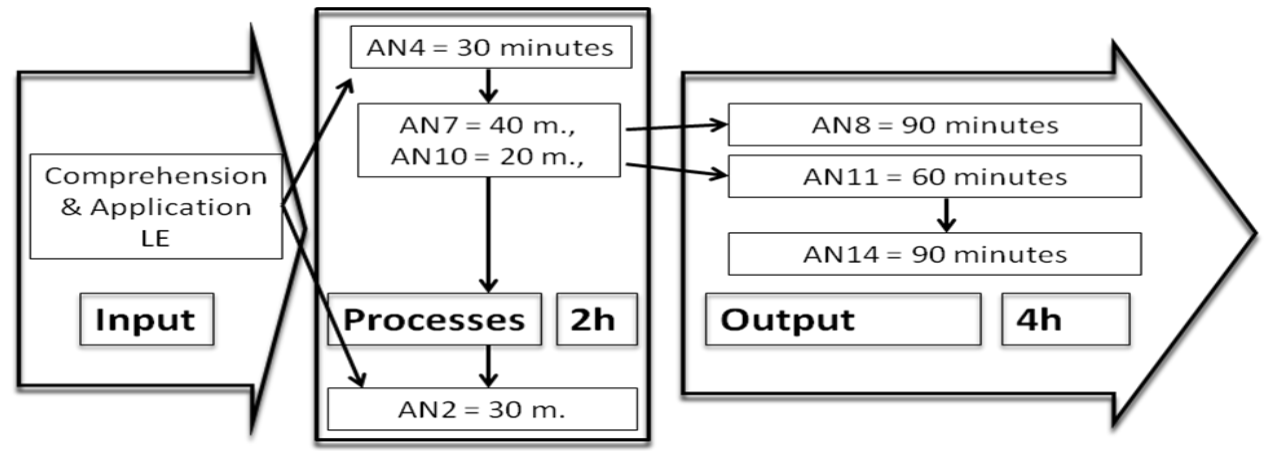

Figure 5. Proposed LE for Analysis level.

Analysis: the Output for Comprehension and Application phase serve and $\mathbf{B}$ phase in this LE. Once in class, the students performs Analysis level activities starting with critical case incident analysis in AN4 and ending with End of class exam on reasons and explanations in AN2. These activities cover the I phase. After the class, the students sharpen their analysis skills both individually and in teams and finally submit a research paper on the subject through AN14. These activities cover the A phase.

Grading of both AP8 and AP10 is the assessment component of phase B while AN2 and AN14 are the assessment tools for I and A respectively. This LE introduces no RC's, seven RS', and five V's activities respectively. This is normal as it is expected that, with the progress of the LE's activities, the RC's will be reduced in favor of the RS'. Thus this LE also fulfills the required conditions.

\subsubsection{Synthesis level of learning's experience}

The Synthesis LE is probably the largest as for its time frame. It needs many intense activities that are done in teams. Team assignment usually takes more time than individual work. It uses six hours of class time and twelve hours of after class activities. According to our time plan, it takes three sessions of the course and is divided into three steps. The first step takes its Input as the Output of the Analysis level LE. Then it feeds in its Output to the second step that in turn feeds in its Output to the last step. Figure 6 below shows this sequence on learning activities. Each activity is defined and classified the table in Appendix A. 

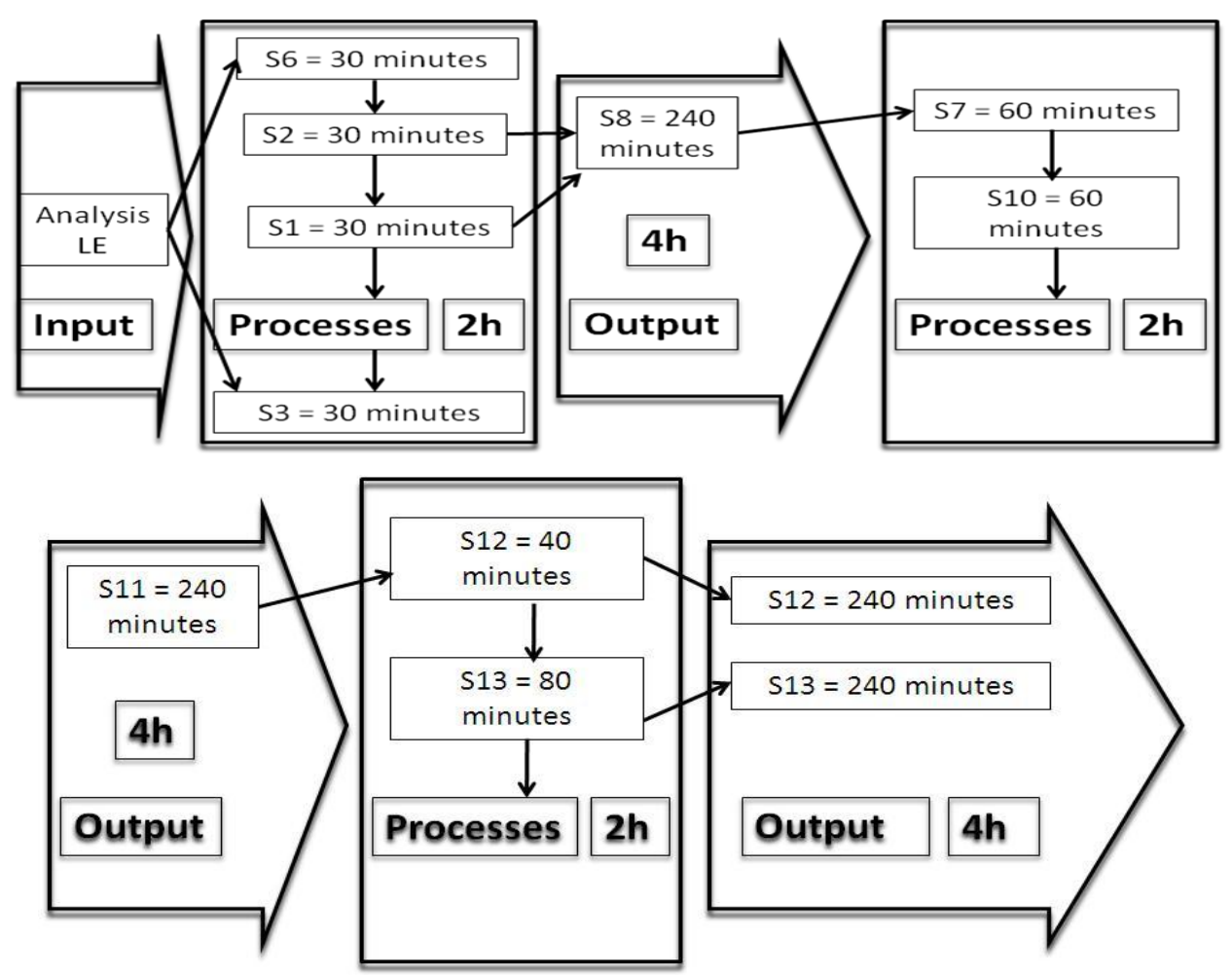

Figure 6. Proposed LEs for Synthesis level.

Analysis: the Output for Analysis phase serve and B phase in this LE first step. Once in class, the students perform synthesis level activities starting with devising a project plan with Gantt chart in S6 and ending with proposing and integrated design in S3. These activities cover the I phase. After the class, the students practice their synthesis skills by researching creating a model in S8. This activity covers the A phase for the first step as well as the $\mathbf{B}$ phase for the second step. Then, once again in class for the second step, the students perform S7 and S10 for I phase. After the class, the students dwell on S11 for the A phase which also covers the $\mathbf{B}$ phase for step three. Then once in class for phase $\mathbf{I}$ of the third step, the students work in teams to create the project and its presentation in S12 and S13. They finish out these tasks in the A phase of the third step.

Grading of AN14 is the assessment tool for B in the first step while grading of S3 and the progress of S8 are the assessment tools for I and A phases of this step respectively. S8 also serves as the assessment tool for B phase of the second step. Grading of S7 is the assessment tool of phase $\mathbf{I}$ of the second step while grading of S11 is the assessment tool for phase $\mathbf{A}$ of this step (and phase B of the third step). Grading of S12 and S13 is the assessment for both $\mathbf{I}$ and $\mathbf{A}$ for the third step. This LE introduces no RC's, ten RS', and nine V's activities respectively. Thus this LE also fulfills the required conditions.

\subsubsection{Evaluation level of learning's experience}

This LE is the final level of learning for our learning experience design. Its time frame is two hours for in-class activities and four hours for after-class activities, as preceded in Table 1. Figure 7 below shows the detailed consequence of the learning activities for this level. The figure shows that, it feeds on the Output of the Synthesis phase and ends up with a life-long learning activity. Each activity is defined and classified the table in Appendix A. 


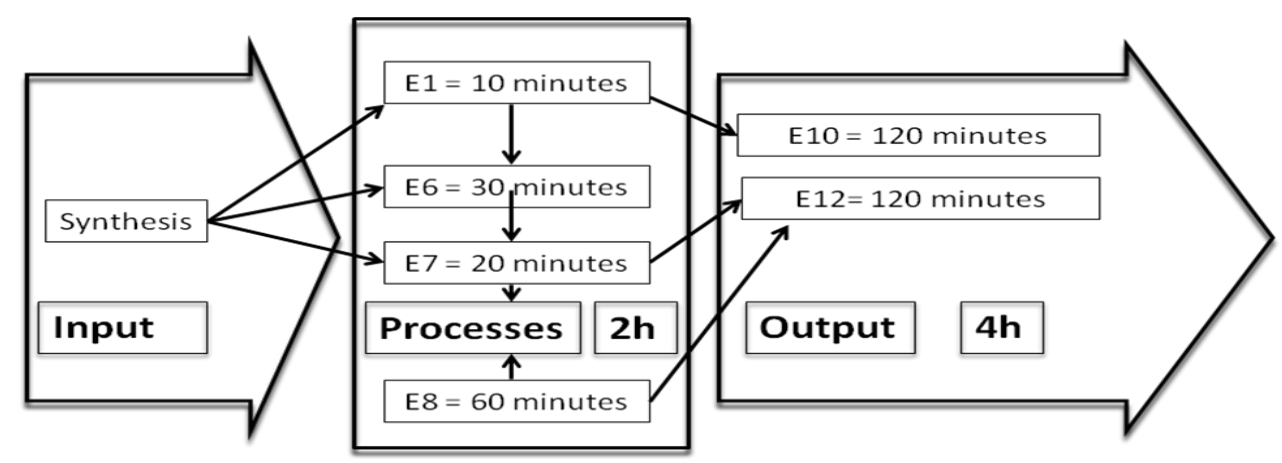

Figure 7. Learning activities sequence for Evaluation LE.

Analysis: the Output for Synthesis phase serves and B phase in this LE. Once in class, students perform Evaluation level activities starting with individual process check in E1 and ending with End of Class Evaluation in E8. These activities cover the I phase. After the class, students embark on life-long learning experiences in E12. These activities cover the A phase. Grading of both S12 and S13 is the assessment component of phase B while E6, E7, and E8 are the assessment tools for I. Finally grading of E11 and E12 are the assessment tool for A. This LE introduces three RC's, seven RS', and three V's activities respectively. The RC's resurface again as this LE involves evaluation forms and checklists. Thus this LE also fulfills the required conditions.

\section{DISCUSSION}

This proposed LE integrated design employs fifty six learning activities for the entire leaning experience, distributed before, in, and after the class. It roadmaps six activities for the Access level, eleven activities for the Knowledge level, ten activities for the Comprehension level, six activities for the Application level, seven activities for the Analysis level, ten activities for the Synthesis level and finally seven activates for the Evaluation level. This design follow closely the time frame outlined in table 1. It also caters for incorporation of the affective domain elements in the LE.

A study was conducted for two semesters, using qualitative and quantitative methodologies for data collection and interpretation to measure the effect of using this LE design on students' attitudes, performance and ability to reach the Evaluation level. These data collection methods included probing students views, their documents and projects, interviews, and survey. Two control groups were selected each semester - one is exposed to this LE design and the other isn't - to the experiment. Each group was 120 student strong working in teams of 5 students each. The study showed positive effects of this LE Design on attitudes, performance, and ability to reach the Evaluation level in favor of the first group. It was also noticed that, the performance of the first group is evidently better than the second at both the Synthesis and Value level.

\section{CONCLUSION}

We introduced here implementation of the "Design Helping Mechanism for Active Learning Courses" introduced in [1]. This implementation is presented as an integrated design for a learning experience that covers all levels of Bloom's taxonomy for cognitive domain levels of learning; starting from Access and ending up at Evaluation. This design takes into consideration the time frame for activities weather it is pre, in, or after class activity. This design provides a streamlined combination of several learning experiences where each of which has an assessment component woven in it. The proposed design also provides a balanced mixture of the affective domain elements; namely receive, respond, and value. The designed learning experience was implemented in a college level course, introducing the students to the engineering design process. While learning experience design always will be an iterative process, it is hoped that, this proposed design will serve as a sound starting point for the designer. 
DEVELOPING AN ACTIVE LEARNING EXPERIENCE FOR ACTIVE LEARNING COURSES.

APPENDIX A: correspondence between levels of learning and learning activities.

\begin{tabular}{|l|l|l|l|l|l|l|l|l|l|l|}
\cline { 2 - 8 } \multicolumn{1}{c|}{} & \multicolumn{3}{c|}{ Time } & \multicolumn{3}{c|}{ Location } & \multicolumn{3}{c|}{ Affective } & ACCESS \\
\hline AC1 & L & & & B & & & RC & & & Class Calendar. \\
\hline AC2 & L & & & B & & & RC & & & Course syllabus. \\
\hline AC3 & L & & & B & & & RC & & & Course Web Site. \\
\hline AC4 & L & & & B & & & RC & & & First Day Material (with grading system) \\
\hline AC5 & L & & & B & & & RC & & & Pre-Class Reading \\
\hline AC6 & & & H & & I & & & RS & V & Team learning and Expert table. \\
\hline
\end{tabular}

\begin{tabular}{|c|c|c|c|c|c|c|c|c|c|c|}
\hline & \multicolumn{3}{|c|}{ Time } & \multicolumn{3}{|c|}{ Location } & \multicolumn{3}{|c|}{ Affective } & KNOWLEDGE \\
\hline K1 & L & & & $\mathrm{B}$ & & & $\mathrm{RC}$ & & & Pre-class individual reading of general knowledge of the subject. \\
\hline K2 & & M & & B & & & $\mathrm{RC}$ & & V & $\begin{array}{l}\text { Students Write an essay or journal on general knowledge of the } \\
\text { subject to master terminology. }\end{array}$ \\
\hline K3 & & M & & B & & A & & RS & V & $\begin{array}{l}\text { Individual assignment to review and do minor modification of the } \\
\text { text book examples. }\end{array}$ \\
\hline K4 & & M & & & & A & $\mathrm{RC}$ & & V & Assisted Post-class reading of general knowledge of the subject. \\
\hline K5 & & & $\mathrm{H}$ & & & A & & RS & $\mathrm{V}$ & Team jigsaw reading assignment after the class \\
\hline K7 & L & & & & I & & $\mathrm{RC}$ & & & Take notes \\
\hline K11 & & M & & & I & & $\mathrm{RC}$ & & $\mathrm{V}$ & Watch videos \\
\hline K12 & & M & & & 1 & & & RS & V & $\begin{array}{l}\text { Verbal articulation to list properties of the subject and } \\
\text { interrelationship between its components. }\end{array}$ \\
\hline K14 & & M & & & I & & & RS & & Start of class general knowledge quiz and Process check \\
\hline K16 & & & $\mathrm{H}$ & & I & & $\mathrm{RC}$ & & & Listen to lecture \\
\hline K17 & & & $\mathrm{H}$ & & I & & & RS & V & $\begin{array}{l}\text { Team jigsaw reading assignment in class with team verbal } \\
\text { articulation of gained knowledge. }\end{array}$ \\
\hline
\end{tabular}

\begin{tabular}{|l|l|l|l|l|l|l|l|l|l|l|l|}
\cline { 2 - 9 } \multicolumn{1}{c|}{} & \multicolumn{3}{c|}{ Time } & \multicolumn{2}{c|}{ Location } & \multicolumn{3}{c|}{ Affective } & Comprehension \\
\hline C1 & & M & & B & & & RC & & V & Pre-class reading of textbook problems. \\
\hline C2 & & M & & B & I & & & RS & V & Individual Brainstorm using ideas of the subject. \\
\hline C6 & & M & & & I & & & & V & $\begin{array}{l}\text { Verbal articulation to describe the problem solving techniques } \\
\text { involved in the subject. }\end{array}$ \\
\hline C7 & & M & & & I & & & RS & & $\begin{array}{l}\text { Stop every 20 minutes and do Student process comprehension } \\
\text { probing. }\end{array}$ \\
\hline C8 & & M & & & I & & & RS & & $\begin{array}{l}\text { Start, middle or end of class comprehension quiz and Process } \\
\text { check }\end{array}$ \\
\hline C9 & & & H & & I & & RC & & V & Team Brainstorm using ideas of the subject. \\
\hline C10 & & M & & & I & A & & RS & & $\begin{array}{l}\text { Verbal or written individual comprehension test on restating or } \\
\text { reorganizing the subject facts and processes. }\end{array}$ \\
\hline C13 & & & H & & I & A & & RS & V & Individual problem solving about facts and processes to follow. \\
\hline C14 & & & H & & I & A & & RS & V & $\begin{array}{l}\text { Verbal or written team exercise on explaining effects, trends, } \\
\text { results and solutions. }\end{array}$ \\
\hline C15 & & & H & & I & A & & RS & V & $\begin{array}{l}\text { Verbal or written team exercise to examine, compare, and contrast } \\
\text { the subject facts. }\end{array}$ \\
\hline
\end{tabular}

\begin{tabular}{|c|c|c|c|c|c|c|c|c|}
\hline & \multicolumn{2}{|c|}{ Time } & \multicolumn{2}{|c|}{ Location } & \multicolumn{3}{|c|}{ Affective } & Application \\
\hline AP1 & M & & 1 & & $\mathrm{RC}$ & & $\mathrm{V}$ & Training and Practicing video \\
\hline AP2 & $\mathrm{M}$ & & 1 & & & RS & $\mathrm{V}$ & Structured application exercise \\
\hline AP3 & & $\mathrm{H}$ & 1 & & & RS & $\mathrm{V}$ & Team Brainstorm to demonstrate using facts of the subject. \\
\hline AP8 & & $\mathrm{H}$ & I & A & & RS & V & Individual problem solving applying techniques and processes. \\
\hline AP10 & & $\mathrm{H}$ & I & A & & RS & $\mathrm{V}$ & $\begin{array}{l}\text { Verbal or written team exercise on explaining utilizing effects, } \\
\text { trends, results and solutions. }\end{array}$ \\
\hline AP11 & & $\mathrm{H}$ & I & A & & RS & V & end of class application quiz, mini-capstone projects \\
\hline
\end{tabular}




\begin{tabular}{|c|c|c|c|c|c|c|c|}
\hline & \multicolumn{2}{|c|}{ Time } & \multicolumn{2}{|c|}{ Location } & \multicolumn{2}{|c|}{ Affective } & Analysis \\
\hline AN2 & $\mathrm{M}$ & & \begin{tabular}{l|l|}
1 \\
\end{tabular} & & \begin{tabular}{l|l|} 
RS \\
\end{tabular} & & End of class exam on reasons and explanations (analysis level). \\
\hline AN4 & M & & 1 & & RS & & Critical incident analysis \\
\hline AN7 & & $\mathrm{H}$ & I & & RS & $\mathrm{V}$ & $\begin{array}{l}\text { Team exercise on reasons and consequences of following different } \\
\text { problem solving routs. }\end{array}$ \\
\hline AN8 & & $\mathrm{H}$ & I & & RS & $\mathrm{V}$ & $\begin{array}{l}\text { Team exercise on dissection of whole some into basic components } \\
\text { and explain inner relationships. }\end{array}$ \\
\hline AN10 & M & & I & $\mathrm{A}$ & RS & $\mathrm{V}$ & $\begin{array}{l}\text { Individual verbal or written articulation on reasons and effects } \\
\text { relationships and predications of effects of changes. }\end{array}$ \\
\hline AN11 & M & & I & A & RS & $\mathrm{V}$ & $\begin{array}{l}\text { Individual verbal or written articulation on dissection of whole into } \\
\text { parts and vice versa. }\end{array}$ \\
\hline AN14 & & $\mathrm{H}$ & & A & RS & V & $\begin{array}{l}\text { Written research papers with an elaborate discussion on analysis of } \\
\text { findings. }\end{array}$ \\
\hline
\end{tabular}

\begin{tabular}{|c|c|c|c|c|c|c|c|}
\hline & Time & & Locati & & Affective & & Synthesis \\
\hline S1 & M & & 1 & & RS & V & Create team deployment chart for project execution. \\
\hline S2 & $M$ & & 1 & A & RS & $\mathrm{V}$ & Create working road map with critical path. \\
\hline S3 & M & & 1 & & RS & $\mathrm{V}$ & Propose an integrated design. \\
\hline S6 & & $\mathrm{H}$ & 1 & $\mathrm{~A}$ & RS & $\mathrm{V}$ & Individually devise a project plan with Gantt Chart. \\
\hline S7 & & $\mathrm{H}$ & 1 & A & RS & $\mathrm{V}$ & Team design of project plan with Gantt Chart. \\
\hline S8 & & $\mathrm{H}$ & 1 & $\mathrm{~A}$ & RS & $\mathrm{V}$ & Research creating a model. \\
\hline S10 & & $\mathrm{H}$ & 1 & A & RS & $\mathrm{V}$ & Team Brainstorming creating a model. \\
\hline S11 & M & & & A & RS & $\mathrm{V}$ & Computer simulations to modify design parameters. \\
\hline $\mathrm{S} 12$ & $M$ & & & $\mathrm{~A}$ & RS & & Team assignment for Create a project poster presentation. \\
\hline $\mathrm{S} 13$ & & $\mathrm{H}$ & & A & RS & V & Team creating an artifact or product. \\
\hline
\end{tabular}

\begin{tabular}{|c|c|c|c|c|c|c|c|c|c|}
\hline & \multicolumn{3}{|c|}{ Time } & \multicolumn{2}{|c|}{ Location } & \multicolumn{3}{|c|}{ Affective } & Evaluation \\
\hline E1 & $\mathrm{L}$ & & & 1 & & & RS & & Individual process check \\
\hline E6 & & $M$ & & I & & $\mathrm{RC}$ & RS & V & Team peer Assessment. \\
\hline E7 & & $M$ & & I & & & RS & & Team process check \\
\hline E8 & & M & & I & & & RS & $\mathrm{V}$ & $\begin{array}{l}\text { End of class evaluation test to compare designs, models, or } \\
\text { products. }\end{array}$ \\
\hline E10 & $\mathrm{L}$ & & & $\mathrm{I}$ & A & & RS & & Checklist self evaluation of work quality. \\
\hline E11 & $\mathrm{L}$ & & & $\mathrm{I}$ & A & & RS & & Individual self Assessment. \\
\hline E12 & & & $\mathrm{H}$ & $\mathrm{I}$ & A & $\mathrm{RC}$ & RS & $\mathrm{V}$ & Lifelong learning experiences. \\
\hline
\end{tabular}

\section{REFERENCES}

[1] Salem, A. Z., A Design Helping Mechanism For Active Learning Courses, (2011), EDULEARN11, the 3rd annual International Conference on Education and New Learning Technologies, Barcelona (Spain).

[2] Laurie Richlin, Blueprint for learning: Constructing College courses To FACILITATe, ASSESS, AND DOCUMENT LEARning. First Edition, 2006. Published by Stylus Publishing, LLC

[3] L. Dee Fink, Creating Significant Learning Experiences. An InTEgrated APPROACH To Designing College Courses. (2003) By John Wiley \& Sons, InC.

[4] Bonwell, C. C. 1992-93. Risky Business: Making ACtive Learning a Reality. Teaching Excellence, 4 (3): entire issue. Available from POD Network in Higher Education, P.O. Box 9696, Ft. Collins CO 80525.

[5] Wiggins, G. 1998. Educative Assessment: Designing Assessments to InForm AND Improve Student Performance. San Francisco: Jossey-Bass.

[6] Barry W. McNeill, Lynn Bellamy, and Veronica A. Burrows, Introduction to ENGineEring Design The WorkBook, Tenth Edition (2002). Technical Editors: Sallie Foster \& Don Butler, College of Engineering and Applied Sciences, Arizona State University

[7] Ames, C., \& Archer, J. (1988). Achievement goals in the classroom: students' learning strategies and motivation processes. Journal of Educational Psychology, 80(3), 260e267. 
[8] Bloom, B. S., \& Krathwohl, D. R. (1956). Taxonomy of Educational Objectives: The classification of educational goals, by a committee of college and university examiners. Handbook I: Cognitive Domain. New York: Longman Green.

[9] Robert Kleinsasser, Bloom's taxonomy of educational objectives, (1996), (School of Languages and Comparative Cultural Studies, UQ). Teaching and Educational Development Institute, The University of Queensland, Prepared by Geoff Isaacs, TEDI, 1996.

[10] Anderson, L. W., \& Krathwohl, D. R. (Eds.). (2001). A TAXONOMY FOR LEARNiNG, TEACHING, AND ASSESSING: A revision of Bloom's Taxonomy of Educational Objectives. New York: Addison Wesley Longman.

[11] Joel A. Michael, Harold I. Modell 2003. ACTIVE LeARning IN SECONDARY AND College Science Classrooms, A Working Model for Helping the Learner TO LEARN. By Lawrence Erlbaum Associates, Inc. 10 Industrial Avenue, Mahwah, NJ 07430.

[12] Anderson, R. S., \& Speck, B. W. (Eds.). (1998, Summer). Changing THE WaY WE GRADE STUDENT PERFORMANCE: Classroom assessment and the new learning paradigm. New Directions for teaching and learning, No. 74. San Francisco: Jossey-Bass.

[13] Angelo, T. A., \& Cross, K. P. (1993). Classroom assessment TeChniQues: $A$ handbook for college teachers (2nd ed.). San Francisco: Jossey-Bass.

[14] Bean, J. C., \& Peterson, D. (1998). Grading classroom participation. In R. S. Anderson \& B. W. Speck (Eds.), Changing THE WAY WE GRAde STUdent PERFORMANCE: Classroom assessment and the new learning paradigm (pp. 33-40). New Directions for Teaching and Learning, No. 74. San Francisco: Jossey-Bass.

[15] Alverno College Faculty. (1994). STUdent ASSESSMENT-AS-LEARNing AT Alverno College. Milwaukee, Wis.: Alverno College.

[16] Johnson, D. W., Johnson, R., \& Smith, K. (1991). Cooperative learning: Increasing college faculty instructional activity. ASHE-ERIC Higher Education Report No. 4. Washington, DC: George Washington University, School of Education and Human Development.

[17] Halpern, D., ed. 1994. Changing College Classrooms: New TeaChing AND LEARNING STRATEGIES IN AN INCREASINGLY COMPLEX WORLD.

[18] Bean, J. C. 1996. Engaging Ideas: The Professor's Guide to Integrating Writing, Critical Thinking, and Active Learning in the Classroom. San Francisco: Jossey-Bass.

[19] Chapman, D. W. (2000). Designing problems for motivation and engagement in the PBL classroom. Journal on Excellence in College Teaching, 11(2\&3), 73-82.

[20] Johnson, D. W., Johnson, R., \& Smith, K. (1998). ACTIVE LEARNING: COOPERATION IN THE COLLEGE CLASSROOM. Edina, MN: Interaction Book Company.

[21] Fabry, V. J., Eisenbach, R., Curry, R. R., \& Golich, V. L. (1997). Thank you for asking: Classroom Assessment Techniques and students' perceptions of learning. Journal on Excellence in College Teaching, 8(1), 3-21.

[22] Andrews, J. D. W. (1980, Fall/Winter). The verbal structure of teacher questions: Its impact on class discussion. POD Quarterly, 2(3\&4), 129-163.

[23] Grasha, A. F., (1972). Observations on relating teaching goals to student response styles and classroom methods. American Psychologists, 27, 144-147.

[24] Salem, A. Z., (2011). A Mobile Aid Tool for Crafting Active Learning Experiences. $10^{\text {th }}$ European Conference on e-Learning ECEL-2011, University of Brighton, Brighton, UK. 